\title{
Primary ovarian high-grade endometrial stromal sarcoma: a case report
}

\author{
Ji Sun Lee ${ }^{1}$, Dayong Lee ${ }^{1}$, Jisun Lee ${ }^{1}$, Man-Hoon Han², Dae Gy Hong ${ }^{3}$ and Hyun Jung Lee ${ }^{1 *}$ (D)
}

\begin{abstract}
Background: Primary ovarian high-grade endometrial stromal sarcoma is a very rare disease. Even though it has poor prognosis, the gold standard treatment has not been established owing to its rarity. This report aimed to present therapeutic options for primary ovarian high-grade endometrial stromal sarcoma.

Case presentation: A 49-year-old Asian woman presented with disseminated intravascular coagulation due to ruptured primary high-grade ovarian endometrial stromal sarcoma with multiple intraperitoneal metastases. After the initial surgery, the patient underwent adjuvant chemotherapy with three courses of Adriamycin $\left(75 \mathrm{mg} / \mathrm{m}^{2}\right)$. We performed the secondary debulking operation including total hysterectomy, metastasectomy, omentectomy, peritonectomy, appendectomy, and hyperthermic intraperitoneal chemotherapy (paclitaxel $175 \mathrm{mg} / \mathrm{m}^{2}$ ). Currently she has been alive for 28 months under a new chemotherapy regimen.
\end{abstract}

Conclusion: We suggest cytoreductive surgery with hyperthermic intraperitoneal chemotherapy could be a therapeutic option for primary high-grade ovarian endometrial stromal sarcoma with peritoneal dissemination.

Keywords: Primary ovarian high-grade endometrial stromal sarcoma, HIPEC

\section{Background}

Endometrial stromal sarcoma (ESS) is a rare malignant tumor of the uterus, which accounts for $0.2 \%$ of all uterine malignancies and less than $10 \%$ of the all uterine sarcomas $[1,2]$. ESS originates from invasive proliferation of cells that resembles normal proliferative endometrial stromal cells [3]. The mesenchymal neoplasm occurs mainly in the uterine corpus, but it also originates from extrauterine sites such as ovary, vagina, Fallopian tube, bladder, small bowel, colon, peritoneum, etc. [4, 5]. Although uterine endometrial stromal sarcoma is a relatively well-known disease, data regarding the management of primary ovarian ESS are scarce and limited due to its rarity. To date, reported cases of ovarian ESS are less than 100, and most of them are low-grade ESSs [6].

*Correspondence: obgy1019@hotmail.com

1 Department of Obstetrics and Gynecology, School of Medicine, Kyungpook National University, Daegu 41944, Republic of Korea Full list of author information is available at the end of the article
While low-grade ESS shows an indolent clinical course and a relatively good prognosis, high-grade ESS has poor prognosis due to rapid progression of the disease and high incidence of recurrence and metastasis. Treatment includes surgery and adjuvant therapies including chemotherapy and radiation therapy, but the gold standard has not been determined because of the limited number of cases $[5,7]$.

Here we describe a case of ruptured primary highgrade ovarian ESS with multiple intraperitoneal metastases being treated with cytoreductive debulking surgery and hyperthermic intraperitoneal chemotherapy (HIPEC) followed by adjuvant chemotherapy.

\section{Case presentation}

A 49-year-old Asian woman presented with severe abdominal distension and dyspnea. She suffered from the feeling of swelling abdomen, dull nature abdominal discomfort and pain, edema in both legs, and dyspnea from 3 weeks before her visit. She visited another hospital original author(s) and the source, provide a link to the Creative Commons licence, and indicate if changes were made. The images or other third party material in this article are included in the article's Creative Commons licence, unless indicated otherwise in a credit line to the material. If material is not included in the article's Creative Commons licence and your intended use is not permitted by statutory regulation or exceeds the permitted use, you will need to obtain permission directly from the copyright holder. To view a copy of this licence, visit http://creativecommons.org/licenses/by/4.0/. The Creative Commons Public Domain Dedication waiver (http://creativeco mmons.org/publicdomain/zero/1.0/) applies to the data made available in this article, unless otherwise stated in a credit line to the data. 
2 days prior to her visit and was transferred to our emergency room owing to huge ovarian cystic mass occupying almost all of the abdominal cavity and large amount of left pleural effusion on computed tomography (CT) scan. On initial vital sign assessment, her blood pressure was stable and she had tachycardia but no fever. Her laboratory findings showed anemia (hemoglobin $8.3 \mathrm{~g} /$ $\mathrm{dL}$ ), leukocytosis [white blood cells (WBC) $21.00 \times 10^{3} /$ $\mu \mathrm{L}$, C-reactive protein (CRP) elevation of $25.8 \mathrm{mg} / \mathrm{dL}$ with prolongation of prothrombin time (PT) (90.4 seconds), PT international normalized ratio (INR) [8], and activated partial thromboplastin time (aPTT) (no coagulation), which could possibly imply disseminated intravascular coagulation (DIC). Physical examination showed abdominal distension, severe tenderness, and rebound tenderness in the whole abdomen. Due to severe dyspnea and abdominal distension, chest arrow insertion at left lung and paracentesis were performed, draining approximately $850 \mathrm{~mL}$ and $2 \mathrm{~L}$, respectively. While performing transfusion, we reexamined dynamic abdomenpelvis CT scan and found $30-\mathrm{cm}$-sized multiseptated cystic mass and peritoneal thickening with large amount of ascites suggesting ovarian malignancy and peritoneal carcinomatosis (Fig. 1). The patient's preoperative cancer antigen 125 (CA125) level showed a significant increase with $674.3 \mathrm{U} / \mathrm{mL}$, human epididymis protein 4 (HE4) was $286.4 \mathrm{pmol} / \mathrm{L}$, and premenopausal/postmenopausal risk of ovarian malignancy algorithm (ROMA) index was $86.67 \% / 92.83 \%$. The other tumor markers such as carbohydrate antigen 19-9 (CA19-9), carcinoembryonic antigen (CEA), and alpha-fetoprotein (AFP) were within normal range. With all the results combined, rupture of a malignant ovarian tumor was suspected, and an emergent operation was planned.

On the initial operation findings, ruptured $30-\mathrm{cm}$ sized right ovarian multiseptated cystic mass showing diffuse adhesion to retroperitoneum, abdominal wall, and uterus was identified. Although frozen section biopsy from the right ovarian mass was revealed as a poorly differentiated carcinoma, debulking surgery including hysterectomy could not be performed owing to persistent oozing pattern bleeding from multiple sites, which was due to DIC. We performed bilateral salpingo-oophorectomy and partial omentectomy. The pathologic diagnosis of the right ovary was high-grade stromal sarcoma with features of brisk mitosis (30-40/ high-power field), focal necrosis, adenofibromatous component, endometriosis with mucinous metaplasia, and hypercellular stroma (Fig. 2). The tumor consisted of monotonous uniform cells with endometrial stromal differentiation [8] (Fig. 2A). Mitotic figures were frequent (Fig. 2B), and highly atypical neoplastic cells were noted (Fig. 2C). Metastasis to omentum was also identified. On immunohistochemistry, tumor cells were positive for CD10 (Fig. 2D), Cyclin D1, and FOXL 2 and positive focally for desmin and smooth muscle actin (SMA). They were negative for beta-catenin and inhibin A. After the surgery, endometrial biopsy was done for excluding metastasis from the endometrium, and the pathologic result was nonspecific. The patient underwent adjuvant chemotherapy with three courses of Adriamycin $\left(75 \mathrm{mg} / \mathrm{m}^{2}\right)$. On the follow-up CT scan

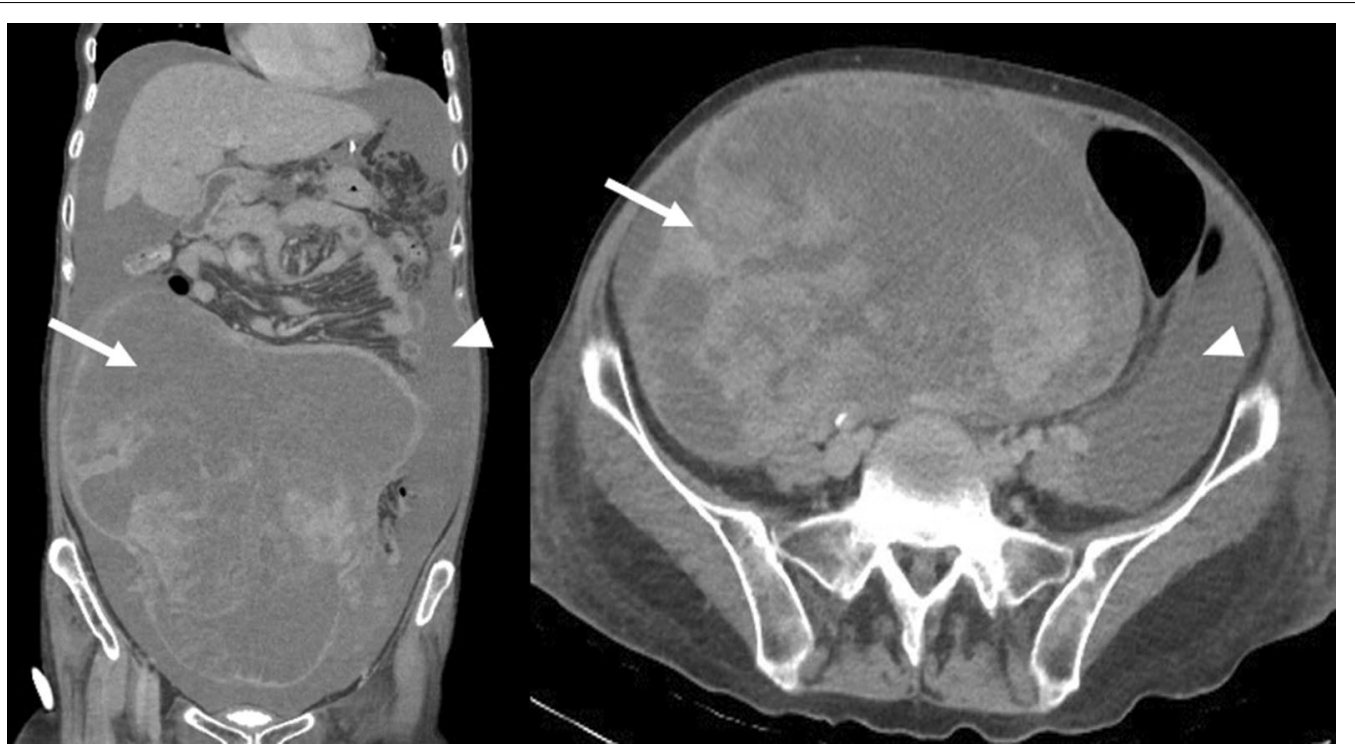

Fig. 1. Computed tomography scan showed a 30-cm-sized irregularly hyperenhancing mass (arrow) with large amount of ascites (arrow head) and peritoneal thickening suggesting ovarian malignancy with peritoneal carcinomatosis 


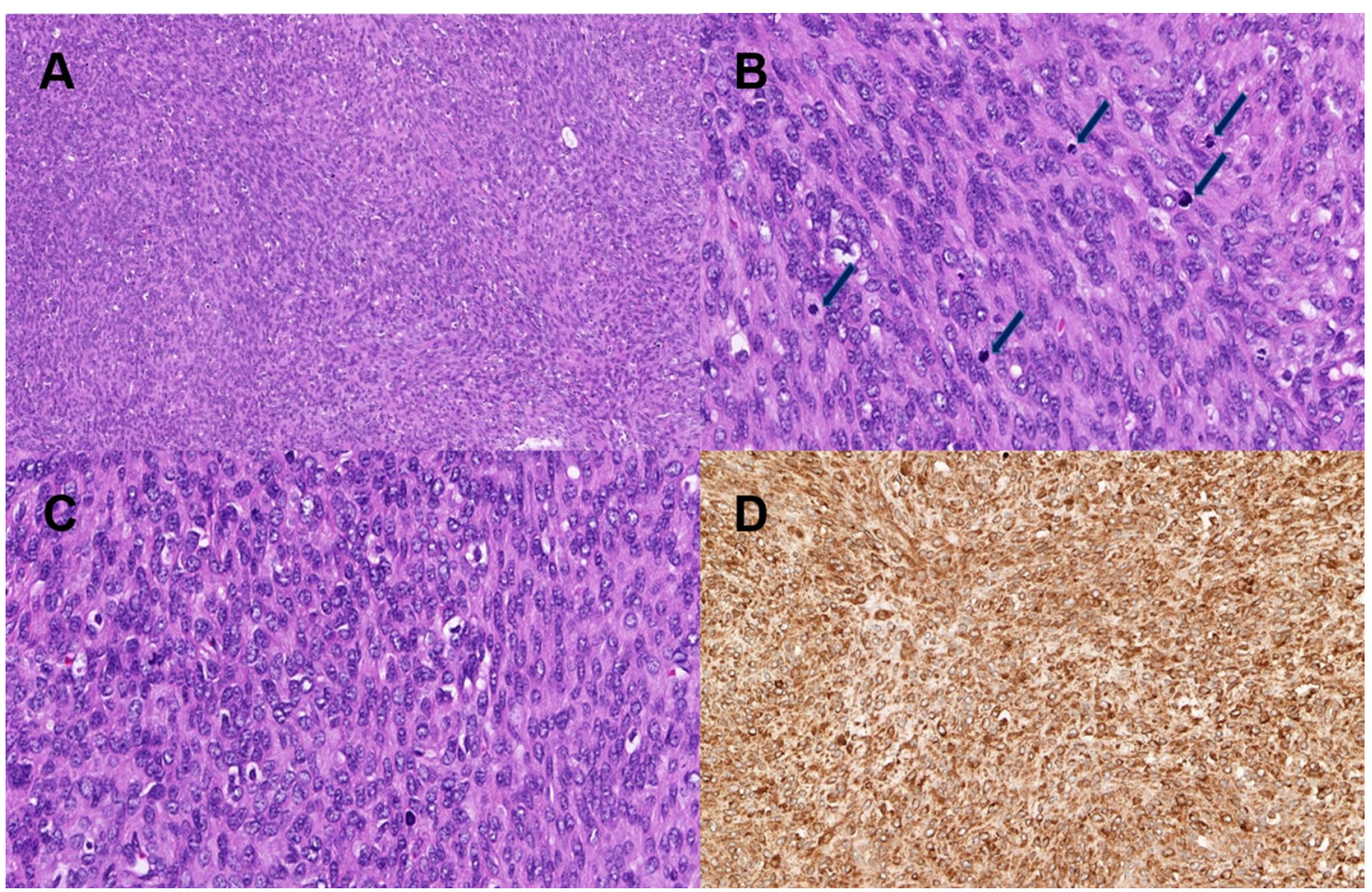

Fig. 2. The tumor consisted of monotonous uniform cells with endometrial stromal differentiation (A). Mitotic figures (arrows) were frequent (B), and highly atypical neoplastic cells were noted (C). On immunohistochemistry, tumor cells were positive for CD10 (D)

that was performed 6 months after the chemotherapy, new 11-mm-sized probable seeding nodules in the right omentum and left paracolic gutter were seen. A $1.5-\mathrm{cm}$-sized partly solid nodule in the right upper lung field was also identified on the chest CT. As for the lung lesion, we had both primary and metastatic lesion in mind, and planned to perform the surgery separately.

We performed the secondary debulking operation including total hysterectomy, metastasectomy, omentectomy, peritonectomy, appendectomy, and HIPEC (paclitaxel $175 \mathrm{mg} / \mathrm{m}^{2}$ ). In the final pathologic report, it was confirmed that the uterine cervix, myometrium, and endometrium had no specific finding except atrophy, which excludes the possibility of endometrial origin malignancy. Peritoneum, omentum, and appendix specimens were confirmed as metastatic high-grade endometrial stromal sarcoma. Two months after the surgery, the patient underwent another right upper lung lobectomy operation, and the biopsy was revealed as adenocarcinoma, which means double primary malignancy. Currently, she has been alive for 28 months under a new chemotherapy regimen: paclitaxel $\left(175 \mathrm{mg} / \mathrm{m}^{2}\right)$ and ifosfamide $\left(1.6 \mathrm{~g} / \mathrm{m}^{2}\right)$.

\section{Discussion}

Primary ovarian endometrial stromal sarcoma is an extremely uncommon entity with only about 100 cases reported in the literature so far. The sites of extrauterine ESS include the ovaries, Fallopian tubes, broad ligament, vagina, bladder, small bowel, colon, pelvic peritoneum, mesentery, and liver, and ovary is the most common primary site of extrauterine ESS $[4,8]$. Since the majority of ESS originates from uterine corpus, to prove primary ovarian ESS, a thorough pathologic evaluation of uterus is essential to exclude the possibility of metastasis, which was confirmed in our case [6]. Most of the tumors occur in postmenopausal women, especially in the fifth and sixth decade. Although patients with uterine ESS typically complain about abnormal vaginal bleeding or pelvic pain, ovarian ESS usually presents with nonspecific symptoms such as abdominal distension and pain or both and is sometimes asymptomatic. Most ovarian ESSs are diagnosed in advanced stages with tumor extension beyond ovaries [9]. It has been reported that tumor markers such as CA125 could be less sensitive in these tumors than in epithelial ovarian cancers [10], but preoperative CA125 in this case was highly elevated (674.3 U/ $\mathrm{mL}$ ) and decreased dramatically after surgery and chemotherapy to normal reference range. 
Previously, ESS was categorized in low- and high-grade tumors on the basis of its mitotic counts. However, the newly released 2014 WHO classification divides "endometrial stromal and related tumors" into the following five types of tumors: endometrial stromal nodule (ESN), low-grade endometrial stromal sarcoma (LG-ESS), highgrade endometrial stromal sarcoma (HG-ESS), undifferentiated uterine sarcoma (UUS), and uterine tumor resembling ovarian sex cord tumor (UTROSCT) [11]. Regarding primary ovarian ESS, according to the 2014 WHO classification system, it can be subcategorized as low-grade ESS and high-grade ESS [6]. High-grade ESS of ovary is much rarer than LG-ESS of ovary and has a poor prognosis due to its high metastasis and recurrence rate. Our patient with huge ovarian mass over $30 \mathrm{~cm}$ also presented with multiple metastases-disease extension to peritoneum, mesentery, appendix - at the time of diagnosis [International Federation of Gynecology and Obstetrics (FIGO) stage IIIC]. The pleural effusion cytology was negative.

The standard treatment of ESS confined to the uterus is total extrafascial hysterectomy with or without bilateral salpingo-oophorectomy, but the treatment of extrauterine ESS is controversial.[12] One retrospective study in 2007 showed that optimal cytoreduction to $<2 \mathrm{~cm}$ of the residual disease resulted in more favorable outcome in median overall survival compared with suboptimal residual disease in patients with HG-ESS (52 versus 2 months, $p=0.007$ ) [5]. Systemic pelvic and paraaortic lymphadenectomy is not routinely recommended, but dissection of enlarged lymph node is indicated in the case of disseminated or recurrent disease. In cases of primary ovarian ESS, in the absence of specific data, it seems reasonable to adapt the rationale of surgical treatment of uterine sarcoma. If the lesion is confined to the ovary, total hysterectomy and bilateral salpingo-oophorectomy is the mainstay of treatment. Patients with advanced diseases need tumor debulking surgery, while the role of routine systemic lymphadenectomy is still elusive. The role of postoperative adjuvant therapies such as chemotherapy and radiation therapy is unclear and does not have specific evidence of survival benefit. [13]

There have been several retrospective reviews about the possibility of cytoreductive surgery followed by hyperthermic intraperitoneal chemotherapy (HIPEC) to be a promising treatment modality in patients with highgrade uterine sarcoma with peritoneal dissemination [14-16]. Multiple studies have already suggested survival benefits in patients with epithelial ovarian malignancies with peritoneal dissemination when treated by cytoreductive surgery with HIPEC. In addition, in peritoneal carcinomatosis of nongynecological origin such as colon or in primary peritoneal malignancies, survival benefit of cytoreductive surgery and HIPEC has been demonstrated in a number of studies $[17,18]$.

\section{Conclusion}

Primary ovarian high-grade endometrial stromal sarcoma (ESS) is a very rare disease. Even though it has poor prognosis, the gold standard treatment has not been established owing to its rarity. This report aimed to present therapeutic options for primary ovarian high-grade ESS. We suggest cytoreductive surgery with HIPEC could be a therapeutic option for high-grade uterine sarcomas with peritoneal sarcomatosis as well as for primary high-grade ovarian ESS with peritoneal dissemination. Although large studies might be challenging owing to the rarity of the disease, further study is needed.

\section{Acknowledgements \\ The authors has have no commercial, proprietary, or financial interest in the products and companies described in this article.}

\section{Authors' contributions}

JSL wrote the report and made substantial contributions to the conception and design of the manuscript. HJL, DGH, and $\mathrm{MHH}$ critically revised the manuscript and were involved in drafting and critically revising the manuscript as well as revising it critically for important intellectual content. All authors read and approved the final manuscript.

\section{Funding}

The authors received no specific funding for this study.

Availability of data and materials

All data generated or analyzed during this study are included in this published article.

\section{Declarations}

Ethics approval and consent to participate

Not applicable.

\section{Consent for publication}

Written informed consent was obtained from the patient for publication of this case report and any accompanying images. A copy of the written consent is available for review by the Editor-in-Chief of this journal.

\section{Competing interests}

The authors declare that they have no competing interests.

\section{Author details}

${ }^{1}$ Department of Obstetrics and Gynecology, School of Medicine, Kyungpook National University, Daegu 41944, Republic of Korea. ${ }^{2}$ Department of Pathology, School of Medicine, Kyungpook National University, Daegu 41944, Republic of Korea. ${ }^{3}$ Department of Obstetrics and Gynecology, School of Medicine, Kyungpook National University, Kyungpook National University Chilgok Hospital, Daegu 41404, Republic of Korea.

Received: 26 April 2021 Accepted: 25 June 2021

Published online: 03 August 2021

\section{References}

1. Brustmann H, Geiss IM, Hinterholzer S. Undifferentiated endometrial sarcoma of the ovary: a case report with review of recent literature and 
discussion of lacking specificity of CD10 immunoreactivity. Pathol Res Int. 2010;5:20.

2. Chang KL, Crabtree GS, Lim-Tan SK, Kempson RL, Hendrickson MR. Primary extrauterine endometrial stromal neoplasms: a clinicopathologic study of 20 cases and a review of the literature. Int J Gynecol Pathol. 1993;12(4):282-96.

3. Back JA, Choi MG, Ju UC, Kang WD, Kim SM. A case of advanced-stage endometrial stromal sarcoma of the ovary arising from endometriosis. Obstetr Gynecol Sci. 2016;59(4):323-7.

4. Efared B, Sidibé IS, Erregad F, Hammas N, Chbani L, El Fatemi H. Extrauterine low grade endometrioid stromal sarcoma arising from ovarian endometriosis: a case report and review of the literature. Gynecol Oncol Res Pract. 2019;6(1):2.

5. Leath CA III, Huh WK, Hyde J Jr, Cohn DE, Resnick KE, Taylor NP, et al. A multi-institutional review of outcomes of endometrial stromal sarcoma. Gynecol Oncol. 2007;105(3):630-4.

6. Xie W, Bi X, Cao D, Yang J, Shen K, You Y. Primary endometrioid stromal sarcomas of the ovary: a clinicopathological study of 14 cases with a review of the literature. Oncotarget. 2017;8(38):63345.

7. Chia C-C, Wu M-P, Huang K-F, Su C-C. Primary stromal sarcoma of the ovary: a case report. Taiwan J Obstet Gynecol. 2004;43(2):110-2.

8. Puliyath G, Nair MK. Endometrial stromal sarcoma: a review of the literature. Indian J Med Paediatr Oncol. 2012;33(1):1.

9. Masand RP, Euscher ED, Deavers MT, Malpica A. Endometrioid stromal sarcoma: a clinicopathologic study of 63 cases. Am J Surg Pathol. 2013;37(11):1635-47.

10. Patsner B, Mann WJ. Use of serum CA-125 in monitoring patients with uterine sarcoma: a preliminary report. Cancer. 1988;62(7):1355-8.

11. Conklin CM, Longacre TA. Endometrial stromal tumors: the new WHO classification. Adv Anat Pathol. 2014;21(6):383-93.
12. Amant F, Coosemans A, Debiec-Rychter M, Timmerman D, Vergote I. Clinical management of uterine sarcomas. Lancet Oncol. 2009;10(12):1188-98.

13. Barney B, Tward JD, Skidmore T, Gaffney DK. Does radiotherapy or lymphadenectomy improve survival in endometrial stromal sarcoma? Int J Gynecol Cancer. 2009;19:7.

14. Jimenez WA, Sardi A, Nieroda C, Gushchin V. Cytoreductive surgery and hyperthermic intraperitoneal chemotherapy in the management of recurrent high-grade uterine sarcoma with peritoneal dissemination. Am J Obstetr Gynecol. 2014;210(3):259.

15. Sardi A, Sipok A, Baratti D, Deraco M, Sugarbaker P, Salti G, et al. Multiinstitutional study of peritoneal sarcomatosis from uterine sarcoma treated with cytoreductive surgery and hyperthermic intraperitoneal chemotherapy. Eur J Surg Oncol. 2017:43(11):2170-7.

16. Sugarbaker PH. Long-term survival is possible using cytoreductive surgery plus HIPEC for sarcomatosis_case report of 2 patients. Int J Surg Case Rep. 2019;64:10-4

17. Yan TD, Deraco M, Baratti D, Kusamura S, Elias D, Glehen O, et al. Cytoreductive surgery and hyperthermic intraperitoneal chemotherapy for malignant peritoneal mesothelioma: multi-institutional experience. J Clin Oncol. 2009;27(36):6237-42

18. Bakrin N, Gilly F, Baratti D, Bereder J, Quenet F, Lorimier G, et al. Primary peritoneal serous carcinoma treated by cytoreductive surgery combined with hyperthermic intraperitoneal chemotherapy. A multi-institutional study of 36 patients. EJSO. 2013;39(7):742-7.

\section{Publisher's Note}

Springer Nature remains neutral with regard to jurisdictional claims in published maps and institutional affiliations.
Ready to submit your research? Choose BMC and benefit from:

- fast, convenient online submission

- thorough peer review by experienced researchers in your field

- rapid publication on acceptance

- support for research data, including large and complex data types

- gold Open Access which fosters wider collaboration and increased citations

- maximum visibility for your research: over $100 \mathrm{M}$ website views per year

At BMC, research is always in progress.

Learn more biomedcentral.com/submissions 